\title{
Current Algebra and Vector Form Factor of $\boldsymbol{h}_{\mathrm{e} t}$.
}

\author{
A. K. MoHaNer and R. F. MARsIAK \\ Department of Physirs and lstronomy \\ linicessily of Rochester . lorhester. I. I. \\ (Nuom Cimento. 52 A. $96 \mathrm{ti7}(1967)$ )
}

On p. 967. line 11, of this paper please read

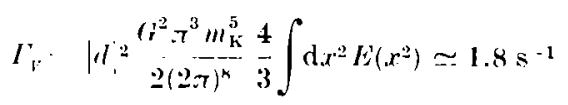

and on the same page. line 14. please read

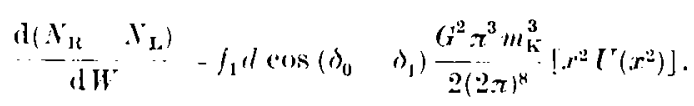

\section{Photoproduction of $p^{0}$ Mesons of Hydrogen, Carbon and Aluminium with Photons of Known Energy.}

H. Bhechechmid, J. P. Down, B. Eraner,

K. Heingotir, K. H. Höhne. S. Raither. J. Rath.J,

I). SCHMIDT. J. H. SMITH and J. H. WEBER

Deutseles Eleltronen-Synchrotron DESY - Hamburg

(Nuovo rimento, 52 A, $1348(1967))$

On p. 135l, line 4, of this paper is written $\mathrm{d} \sigma / \mathrm{d} /=a \cdot b t$. but this formula for the cross-section shoud read do/dt $\cdots a \cdot p^{\prime \prime}$. 